EPiC Series in Engineering
Volume 3, 2018, Pages 1664-1671
HIC 2018. 13th International
Conference on Hydroinformatics

\title{
Application of Delft3d for designing and assessing new solutions to improve sediment input to an erosion prone coast
}

\author{
José Pinho $^{1 *}$, José Coelho ${ }^{1}$, Stênio Venâncio ${ }^{2}$, Luís Vieira ${ }^{1}$, Bárbara Vieira ${ }^{1}$ \\ and José Vieira ${ }^{1}$ \\ ${ }^{1}$ Department of Civil Engineering, University of Minho, 4710-057 Braga, Portugal \\ ${ }^{2}$ Department of Civil Engineering, Federal University of Triângulo Mineiro, Brazil \\ jpinho@civil.uminho.pt
}

\begin{abstract}
The construction of harbor defense structures changes the natural sedimentary fluxes that contribute to feed the coastal drift in the adjacent beaches, in many harbors of the world located at river mouths. This paper presents a numerical modelling work, based on the Delft3D software, to study morphodynamics at the river Lima estuary, Portugal. This model was implemented recurring to a hydroinformatic environment that was constructed at University of Minho along the last two decades. Considering specific hydrodynamic conditions and typical characteristics of the estuarine sediments, the capacity of hypothetical structures to improve transport of sediments to the coast was assessed: (i) a submerged transverse non-erodible dam and (ii) an emerged groin linked to the left embankment located at the upstream section of the harbor. The implemented hydroinformatic environment presents capacities to simulate the complex morphodynamic behavior of river mouths. The preliminary results reveals that the proposed structures can have a positive impact throughout dredging works facilitation by transferring depositional areas during flood events to a location near the coast inside the harbor. Ongoing field acquisition data will be essential to validate depositional patterns under different river discharges and wave conditions.
\end{abstract}

\section{Introduction}

The NW coast of Iberian Peninsula is mainly in a sedimentary deficit status. This situation result from the north-south coastal drift driven by the dominant wave climate, that at this location propagates from the NW direction. However, inadequate management of sediments that reaches the rivers mouths

\footnotetext{
${ }^{*}$ Corresponding author
} 
can aggravate the sediments starvation at the coast. The river Lima basin is a relatively small basin, shared by Portugal and Spain, with low anthropogenic intervention. The construction of two dams in 1992, despite controlling the floods at downstream vulnerable cities, caused changes in the natural conditions of the river flow, attenuating the maximum flows along the estuary and consequently the sediment transport capacity. At the same time the construction of harbour defence structures changed the natural sedimentary fluxes that contribute to feed the coastal drift in the adjacent beaches (Tonnon et al., 2007). Moreover, maintain the navigation channel at the river mouth imply to dredge important volumes of sediments. Indeed, one of the main problems associated with navigable estuaries is siltation, with great impacts, especially, at river mouths or harbour areas. The rising of the estuarine bottom, resulting from the sedimentary deposition, limits the navigability conditions. This is overcome by periodic maintenance carried out through dredging. However, the definition of locations for deposition of dredge sediments in such a way that they can be integrated in the coastal longitudinal drift, is very difficult since it depends on the river flows and wave action. This way, a spatiotemporal characterization of the hydrodynamics and morphological conditions, which determine the sedimentary transport and accumulation/deposition patterns, becomes necessary for proper sediment management.

Development of hydroinformatics tools capable of simulate the complexity of the estuarine and coastal morphodynamic behaviour represents an advantage for analyses, diagnoses and predictions of medium and long term time horizons, including assessment of innovative solutions (eg. Stive et al. 2013) for the management of siltation within coastal and estuarine environments. Among this innovative solutions, work with nature based conceptual solutions (Airoldi et al., 2005; Waterman, 2008) must be equated instead of traditional solutions involving dredging works that are usually expensive and implies cutting the natural feeding of sediments to the coastal stretches (Granja and Pinho, 2012). This means that capacity to simulate complex coastal hydrodynamics resulting from river discharges, waves propagation and sediments transport must be available in proper hydroinformatics environments, complemented with field measured data. Sediment transport models are still based on physical experimental laboratory measured data. Technological developments on sensors for field measurements (eg. Kurkin et al., 2016; Gelfenbaum et al. 2015) brings the opportunity to develop and validate those models.

This work aims explore the potentialities of morphodynamic modelling in an attempt to design and evaluate new solutions to minimize the silting at a river mouth, favouring the sediment exporting to the adjacent coastal beaches or facilitate dredging works (Van Maren et al., 2015). Preliminary results of deposition/erosion modification through the construction of artificial structures are presented. Assessment of both immersed and emerged structures at specific locations in the estuary, in an attempt to facilitate the export of sediments during flood events, is presented for two different structures. This analysis was carried out recurring to a numerical model implemented with Delft3D for the river Lima estuary, that is being used as full scale lab to conduct coastal and estuarine research work.

\section{Methods}

\subsection{Study site}

River Lima basin, located in the northern region of Portugal, has a total drainage area of approximately $2450 \mathrm{~km}^{2}$ (Fig. 1). About $46.5 \%$ of that area is located in Portuguese territory, while the remaining area is located in Spain. This basin has a mean elevation of $447 \mathrm{~m}$ with several peaks above $1300 \mathrm{~m}$, an average annual precipitation in the range of $1300-4200 \mathrm{~mm}$, and an average population density of 112 inhabitants $/ \mathrm{km}^{2}$. The largest contribution to the formation of massive floods comes from the runoff generated in its mid-section. This fact is not only due to the high rainfall events verified in that region, but also to the ability of this area to generate surface runoff due to low soil permeability, 
together with the presence of rugged and deep valleys. Two hydropower plants (Lindoso and Touvedo dams) are in operation since 1992, and their reservoirs represent a significant storage capacity controlling the occurrence of flood events (Pinho et al., 2012).

The study area coincides with the river Lima estuary, that is located between the upstream boundary at Ponte de Lima village weir and the Atlantic Ocean. Three monitoring stations were used to calibrate and validate the numeric model (A - Viana do Castelo, B - Portuzelo and C - Lanheses). The estuary is wider than the upstream sections of the river and presents a very slight slope, leading to siltation, both in riverbed and in its banks. Thus, some islets are formed, which are quickly dominated by vegetation, creating a series of small islands in the area of Viana do Castelo. These islands are inundated only during important flood events or spring tides combined with storm surges. At the mouth the width of the estuary varies from $300 \mathrm{~m}$ near the harbour zone, up to $800 \mathrm{~m}$, near the railway bridge. The accessibility to the harbour is guaranteed by two breakwaters that protects the navigation channel from the high energetic Atlantic wave climate. This navigation channel is narrow and has an average depth of $10 \mathrm{~m}$, that it is maintained by regular dredging works.

According to a previous study (Pinho and Vieira, 2005), there are no tributaries within the estuarine basin able to transport sufficient sediment to cause significant changes in the main river channel. The sediments are mainly transported by the river Lima, depending on the flows discharged at the upstream dams. According to statistical analysis of historical river discharges data, the average annual river flow is around $38 \mathrm{~m}^{3} / \mathrm{s}$. But in the summer season this value can fall to around $5 \mathrm{~m}^{3} / \mathrm{s}$. Flood peak discharges were lowered as a consequence of the construction of the upstream dams in 1992, diminishing the capacity of the river to transport sediments to the shoreline through the estuary. The capacity of the dam's spillways is $3200 \mathrm{~m}^{3} / \mathrm{s}$.
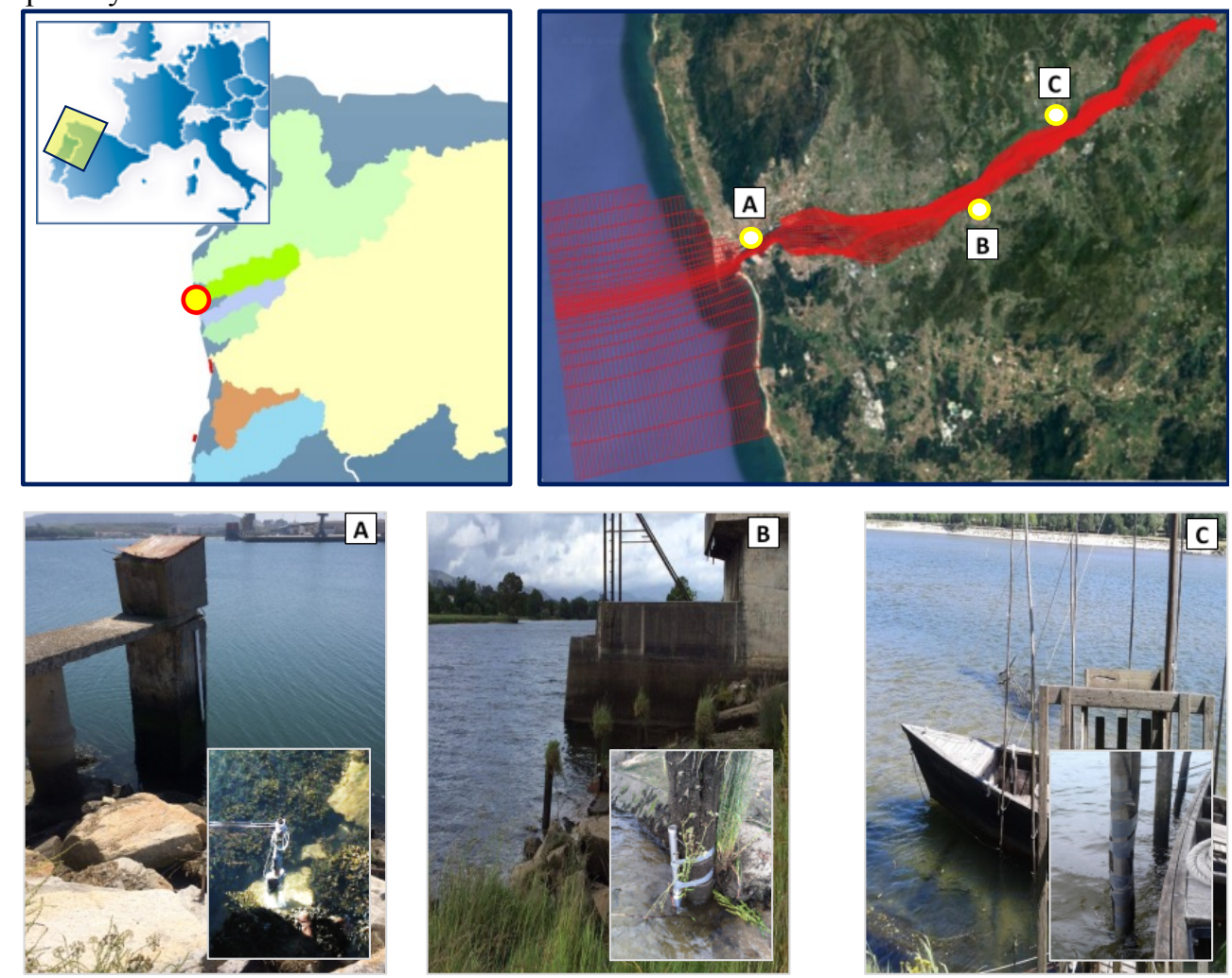

Figure 1: Study site location (upper left panel), grid of river Lima estuary morphodynamic model (upper right panel) and water levels measurement locations for model calibration (lower photos). 


\subsection{Hydroinformatic environment and river Lima estuary model}

The hydroinformatic environment installed at University of Minho for coastal research is mainly based on open source software solutions and is organized in five principal components (Fig. 2): (1) hydrodynamics, (2) morphodynamics, (3) water quality, (4) field devices and (5) integration, pre and post-processing tools. Correct organization, edition and visualization of the large amount of data associated with coastal modelling are of crucial importance for the correct implementation, analysis and interpretation of models results. Unstructured meshes (Shewchuk, 1997) and grids are generated recurring to available tools, like SMS, Delftdashboard and Delft-GUI. Data from different software packages are integrated and exchanged with the aid of a group of utilitarian tools basically developed to perform conversion and writing tasks according to the appropriate data formats. Operationalization of implemented models is also possible recurring to FEWS software (Werner et al., 2012). Finally, some measurements devices are available to acquire field data used in models calibration and validation, including a DGPS device, an ecobathymeter installed in a boat and several pressure devices that are being assembled and configured at University of Minho.

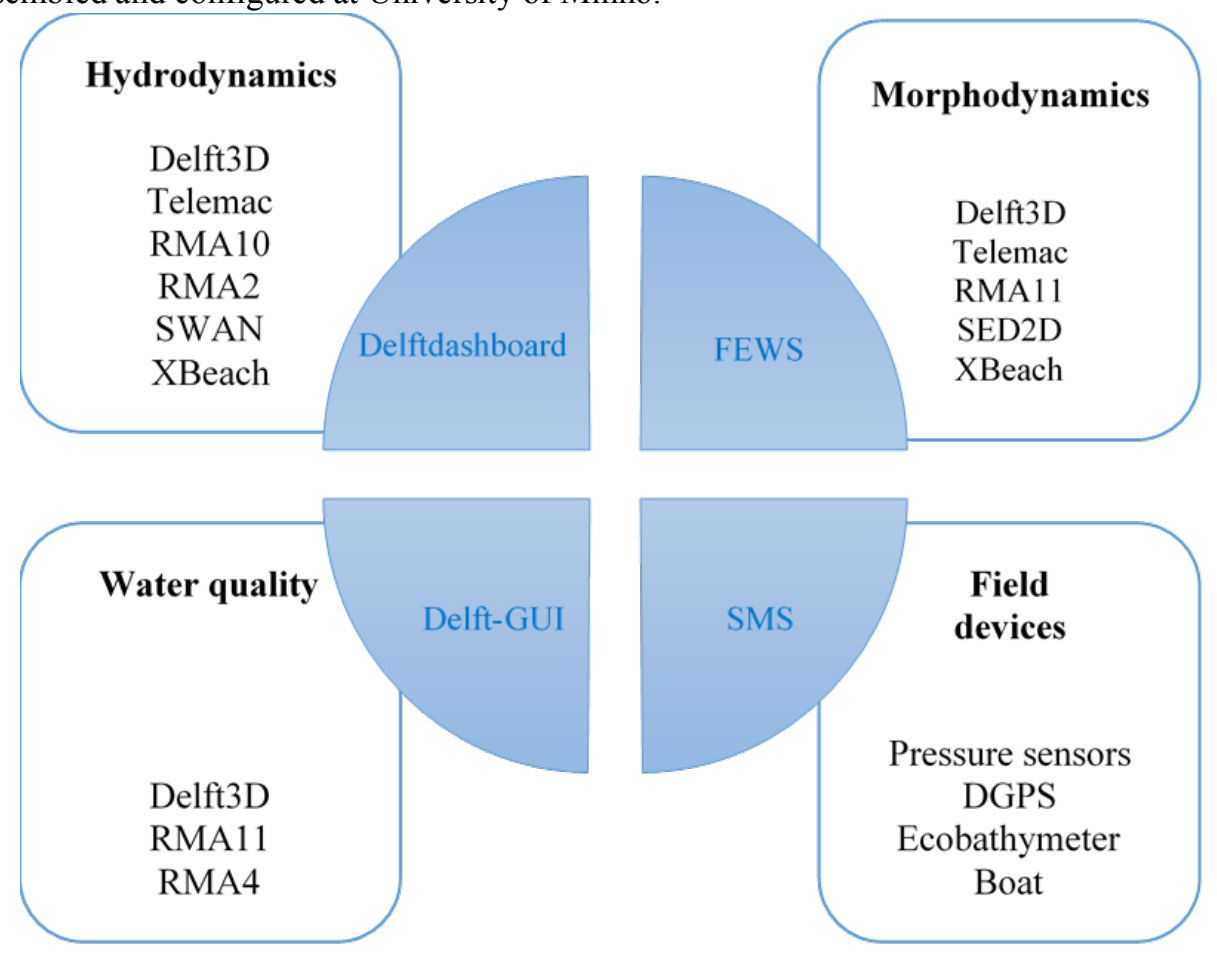

Figure 2: Hydroinformatics environment for coastal models implementation.

The morphodynamic model of the river Lima estuary was implemented using Delft3D software (Deltares, 2011). This software solves the incompressible free-surface 2DH Saint-Venant equations and a sediment transport equation. The estuary was discretized with a grid (Fig. 1) that was defined considering its geometry and a compromise between the spatial resolution requirements and que computational time costs. The bathymetric data used for model set-up was obtained in 2003 and early 2004, by APA (Environment Portuguese Agency), and for the river mouth by the administration of Viana do Castelo Harbor, during the same period. The model was implemented using a grid with a total number of 15558 cells.

At the open boundaries it was considered the average daily flow at the upstream river boundary and the instantaneous tidal elevation at the ocean downstream boundary. Ocean open boundary tidal 
elevations for the monitoring period were obtained from the Portuguese Hydrographic Institute complemented with IHO data. Upstream river flows were obtained at water resources Portuguese database. Sediment concentrations at the open boundaries were assumed equal to the equilibrium concentration at the upstream boundary and a null value was adopted at the ocean boundary.

\subsection{Field data}

This particular study involve fieldwork that consists of measuring water levels and temperature within the estuary. These data were used for model calibration. Pressure sensors were installed at different locations (A, B and C Fig. 1). In addition to measured water levels, flow discharged at Touvedo dam (upstream dam) and tidal astronomic components at the ocean open boundary were considered. The bottom sediments are non-cohesive with mean diameters of $200 \mu \mathrm{m}$.

\subsection{Simulated scenarios}

Different scenarios were defined considering tidal characteristics, upstream river discharges and duration of the simulations. The first scenario was defined considering the conditions that occurred during the monitoring period. In order to simulate and analyse the typical hydrodynamic conditions within the estuary a set of scenarios were defined resulting from the combination of different river discharges $\left(38 \mathrm{~m}^{3} / \mathrm{s}, 400 \mathrm{~m}^{3} / \mathrm{s}, 800 \mathrm{~m}^{3} / \mathrm{s}\right.$ and $\left.3200 \mathrm{~m}^{3} / \mathrm{s}\right)$ and tidal elevations. Morphodynamic scenarios were defined considering river discharge, tidal characteristics and duration of the simulation period. This way it was possible to analyse both long term morphologic patterns and short term influence of flood events.

Behind the hydrodynamic and morphodynamic estuary simulations, two hypothetical structures located at the upstream section of the main harbour channel were analysed recurring to the implemented model: (i) a submerged (below the low-tide water level) transverse non-erodible dam and (ii) an emerged groin linked to the left embankment. Assessment of the structures performance improving the sediments transport towards the estuary mouth was carried out comparing sedimentation patterns resulting after a flood event with a river peak discharge of $3200 \mathrm{~m}^{3} / \mathrm{s}$ during spring tide conditions.

\section{Results and discussion}

Concerning model calibration, comparisons between measured and simulated water levels results present a mean average error that are less than $0,06 \mathrm{~m}$ for the three considered measurement stations. Calibration results revealed a good correlation between simulated and measured values when a Manning roughness coefficient was adopted with a value of $0.015 \mathrm{s.m} \mathrm{m}^{-1 / 3}$, and the horizontal eddy viscosity and diffusivity was considered equal to $1 \mathrm{~m}^{2} / \mathrm{s}$. Using Nash Sutcliffe efficiency (NSE), for example, with the exception at Lanheses station ( NSE $=0.87$ ), all other stations present NSE values above 0.94 . Other metrics (bias - BIAS; root mean squared error - RMSE; mean average error - MAE) were used to assess the performance of the model to simulate water levels along the estuary. The performance of the model improves as we approximate to the river mouth at Viana do Castelo. This can be explained by two reasons: (i) the bathymetric data used at the downstream area of the estuary presented more resolution when compared with the cross sections available for the region of the upstream estuary; (ii) since the simulations were carried out assuming average daily river discharges, hourly fluctuations that were neglected can present a more significant influence at the upstream sections.

The higher depth average velocities are obtained at the river mouth and at the upstream zone of the estuary, in the vicinity of Ponte de Lima town. A detailed analysis at the river mouth, demonstrate that the more intense currents are located in the narrow canal. It is also possible to observe that under the flood river discharge the flux maintains directed towards the sea with no noticeable reflux due to tide. 
Results of morphodynamic simulations showed that the maximum erosion and sedimentation in the estuary are affected by river flows and the tide characteristics. At the central section of the estuary the differences in erosion and sedimentation due to tidal characteristics were almost negligible. It becomes clear that the most dynamic area in terms of erosion and deposition is located at the river mouth for all considered scenarios, with changes in their extent and magnitude according to the river discharges. At this location there are two preferred sedimentation areas: one located near the highway bridge and the other immediately downstream the railway bridge. In the first location the existent islets prove the sedimentary accumulation tendency and at the second, the continuous necessity of dredging the harbor main canal also demonstrate the sedimentary pattern revealed by the morphodynamic simulations. Modelling results for a flood event scenario (Fig.2 a)), showed that under these conditions it is possible to remove sediments that are deposited at the entrance of the harbour channel (blue areas). However, some of these sediments, are immediately deposited downstream, in the central part of the harbour (red areas). This sedimentation implies dredging works after major flood events. Dredge sediments must be transported along the main channel of the harbour to be deposited at the coastal nearshore. The sedimentation pattern associated with the submerged dam (Fig.2 b)) occurs also downstream of the main channel entrance but are less intense, with the deposition occurring in a larger extent of the harbour channel. Finally, the left embankment groin (Fig.2 c)) seems to avoid sedimentation along the narrower zone of the harbour, transferring to the outer basin of the harbour the deposition of sediments. Eventual dredging works became easier since transport distance to devolve sediments to the adjacent beaches are shorter that the ones required for the actual configuration.

\section{Conclusions}

A morphodynamic model of the river Lima estuary was calibrated using field data expressly obtained for that purpose. River flow discharges are determinant for the actual water levels within the estuary, in the upper region of the estuary, while ocean levels determine the behaviour of water levels within the harbour region. For the higher river flow scenario there is an erosional tendency capable of remove all the sediments that are deposited in the narrow estuarine canal located near the railway bridge, which is immediately deposited downstream, within the interior of the harbour. At the central region of the estuary there is an alternate consecutive sequence of erosion and sedimentation zones, which are present for all scenarios involving higher river discharges. It was also concluded that for long term simulations (horizons of 10 years), there are areas with intense sedimentation values. There is a strong possibility of sedimentation at the river mouth and the central area of the harbour, which, moreover, requires dredging works over the years to maintain navigation depth requirements. Dredging sediments should be correctly deposited near the coast in order to properly feed the longitudinal drift. Moreover, the hydroinformatic environment allows to study two different potential interventions to improve the sediments export capacity of the estuary towards the adjacent coastal zone.

Negative impacts associated with the presented solutions to improve sediments transport to the coast were not discussed but are evident. For instance, eventual restrictions to navigation and rising of water levels upstream of the structures during flood events. However, efficient sediment management policies at harbours deserves a major concern since it constitutes one of the key parameters affecting lacking of sediments in erosion prone beaches, all over the world.

The implemented model revealed to be robust and able to represent the hydro- morphodynamics of the river Lima estuary. However, for a development in quantitative analysis, an extension of field campaigns is suggested, in order to improve the available data for comparison with models results, in what concerns sediment characteristics and bathymetric data. 

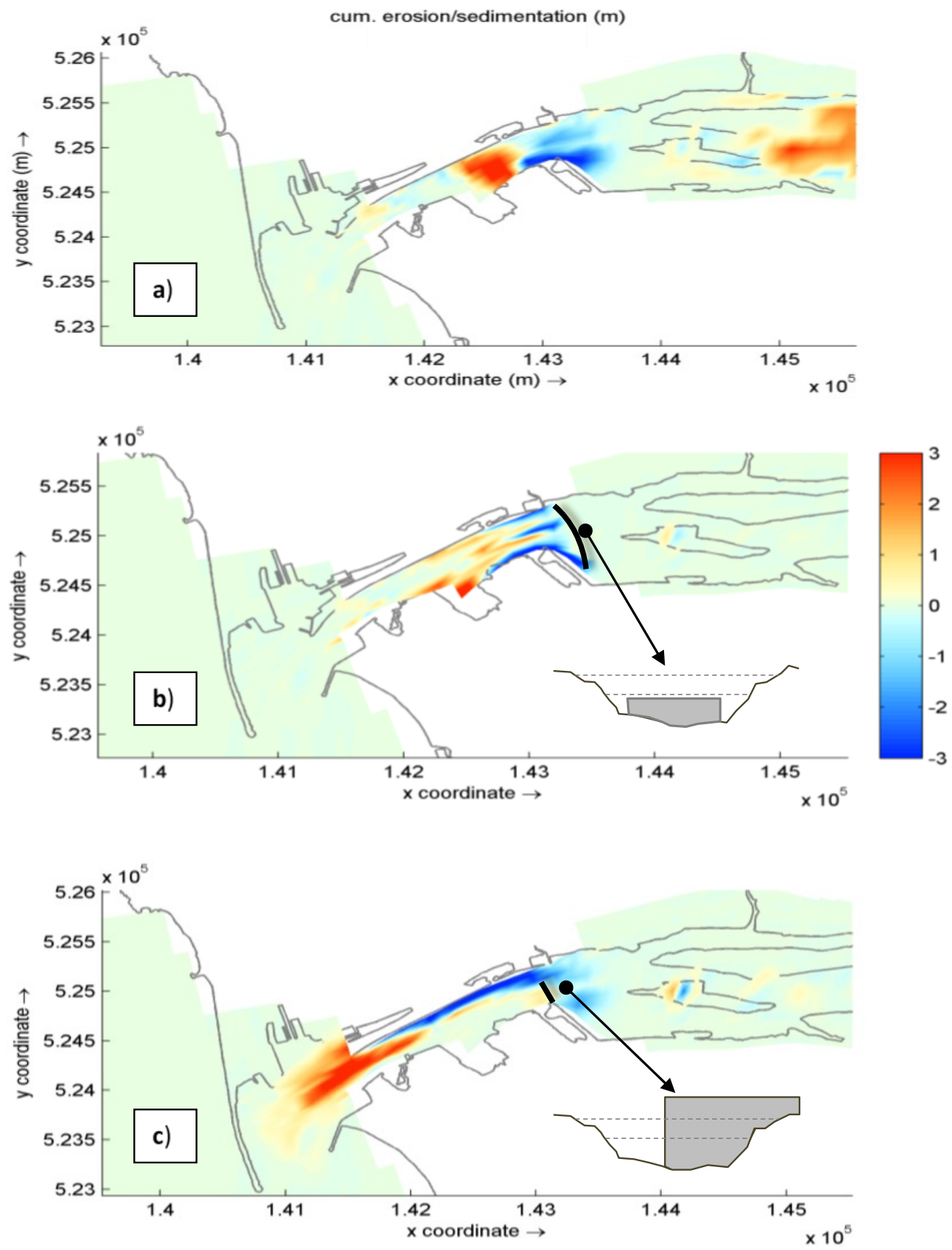

Figura 3: Results of cumulative erosion/sedimentation after a flood event considering: a) the actual estuary mouth configuration, b) a submerged dam at the upstream section of the harbour main channel, and c) an emerged groin at the upstream section of the harbor. 


\section{Acknowledgment}

This research is partially supported by POCTEP/Interreg, project MarRISK (0262_MarRISK_1_E).

\section{References}

Airoldi, L.; Abbiati, M.; Beck, M.W.; Hawkins, S.J.; Jonsson, P.R.; Martin, D.; Moschella, P.S.; Sundelo, A.; Thompson, R.C.; Äberg, P. (2005). An ecological perspective on the deployment and design of low-crested and other hard coastal defence structures. Coastal engineering, 52(10-11), 1073-1087.

D. S. Van Maren, T. Van Kessel, K. Cronin, L. Sittoni The impact of channel deepening and dredging on estuarine sediment concentration. Continental Shelf Research. 95, 2015, 1-14.

Deltares (2011) Delft3D-Flow User Manual - Simulation of multi-dimensional hydrodynamic flows and transport phenomena, including sediments. Deltares, Netherlands, 64p.

Gelfenbaum, G., Stevens, A. W., Miller, I., Warrick, J. A., Ogston, A. S., \& Eidam, E. (2015). Large-scale dam removal on the Elwha River, Washington, USA: Coastal geomorphic change. Geomorphology, 246, 649-668.

Granja, H.; Pinho, J.L.S. (2012) Coastal defense in NW Portugal: the improbable victory. In The Pitfalls of Shoreline Stabilization, Springer, USA: 251-266.

Kurkin, A., Pelinovsky, E., Tyugin, D., Kurkina, O., Belyakov, V., Makarov, V., ... \& Federation, R. (2016). Coastal remote sensing using unmanned ground vehicles. Int. J. Environ. Sci, 1, 183-189.

Pinho J.L.S. and Vieira J.M.P. (2005) Mathematical modeling of salt water intrusion in a Northern Portuguese estuary. Fourth Inter Celtic Colloquium on Hydrology and Management of Water Resouces, Guimarães, Portugal.

Pinho, J.L.S., Ferreira, R., Vieira, L., Schwanenberg, D. (2014). Comparison between two hydrodynamic models for flooding simulations at river Lima basin. Water Resource Management, Springer, v. 29, $\mathrm{n}^{\circ}$ 2, p. 431-444.

Shewchuk JR. (1997) Triangle: Engineering a 2D Quality Mesh Generator and Delaunay Triangulator. Pittsburgh, USA: School of Computer Science, Carnegie Mellon University.

Stive, M. J., de Schipper, M. A., Luijendijk, A. P., Aarninkhof, S. G., van Gelder-Maas, C., van Thiel de Vries, J. S., ... \& Ranasinghe, R. (2013). A new alternative to saving our beaches from sea-level rise: The sand engine. Journal of Coastal Research, 29(5), 10011008.

Tonnon, P. K., Van Rijn, L. C., \& Walstra, D. J. R. (2007). The morphodynamic modelling of tidal sand waves on the shoreface. Coastal Engineering, 54(4), 279-296.

Waterman, R.E. (2008) Integrated coastal policy via Building with Nature. Opmeer Drukkerij, The Hague, The Netherlands.

Werner, M.; Schellekens, J.; Gijsbers, P.; Dijk, M. Van; Akker, O. Van Den; Heynert, K. (2012) The Delft-FEWS flow forecasting system. Environmental Modelling \& Software, pgs. 1-13. 